\title{
Some Emotions Play a Reasonable Role in Akratic Actions, Not a Rational Role
}

\author{
Yu Zhang ${ }^{1, *}$ \\ ${ }^{1}$ Department of Philosophy, Peking University, Beijing 100871, China \\ *Corresponding author.Email: 1901110815@pku.edu.cn
}

\begin{abstract}
According to Donald Davidson, an akratic action is opposed to the agent's better judgment if the agent act freely and intentionally. Davidson says akratic actions are possible and all akratic actions are irrational. However, although akratic actions are possible, akratic actions could be rational. The reasons are that some of these actions are rational; these rational akratic actions are caused by some emotions sometimes, while some emotions cannot make akratic actions rational, including excessive negative emotions, recalcitrant emotions, etc. Therefore, it is reasonable to explain akratic actions caused by these emotions and these emotions not play a rational role in akratic actions.
\end{abstract}

Keywords: Akratic actions, Emotions, Rationality, Reasonableness.

\section{INTRODUCTION}

Weakness of will is called akrasia in the Ancient Greek period because Ancient Greek Philosophy does not have the concept of will. Akrasia means lack of mastery or self-control. Selfcontrol here means a capacity to do best when the agent tempted to do otherwise. Some philosophers deny the possibility of weakness of will, including Socrates, R. M. Hare, etc. Davidson (1970) objects to Socrates' argument and argues that incontinence is possible but irrational. It has a little difference between the concept of incontinence and the concept of weakness of will, especially incontinence emphasizes on being physiologically out of control. However, Davidson uses this concept almost identify with weakness of will. Davidson's argument is: the reason of why we meet the paradox between incontinence and two principles (wanting and better judgment) is that we misunderstand the nature of practical reasoning. Better judgment is conditional judgment and prime facie judgment. Therefore, the fact that we could perform akratic actions violates better judgment. [3] Davidson also claims akratic actions are irrational through analyzing elements of psychoanalytic theory, including "the partitioning of the mind, the existence of a considerable structure in each quasi- autonomous part, and non-logical causal relations between the parts." [4]

However, Nomy Arpaly, Karen Jones, and Christine Tappolet claim that akratic actions are possible and rational, and emotions play a rational role in akratic actions.

\section{ARGUMENT ABOUT EMOTIONS PLAY A RATIONAL ROLE IN AKRATIC ACTIONS}

Firstly, not every akratic action involves emotion. It is called cool akrasia when akratic actions do not involve emotions. Secondly, when akratic actions involve emotions, it is rational to explain akratic actions caused by emotions. Emotions help us track some reasons overlooked by all-thing-considered judgment. McIntyre (1990) uses the case of Huckleberry Finn to reveal that Finn's akratic actions are rationally caused by emotions. Finn violated the better judgment of turning Jim in when he realized the friendship and sympathy. Emotions make Finn consider the factors overlooked by better judgment. [2][6] A Similar case is Nomy Arpaly's (2000) case of a chemistry Ph.D. student, Emily, who abandoned her degree because of the feeling of restlessness, sadness, and ill-motivation. It was a better choice to abandon, although she did not realize that at that moment. 
Arpaly claims that better judgment is just another belief and that the conflict between beliefs and better judgment is inconsistence between beliefs or beliefs and desires. [1] Besides, Karen Jones (2003) believes emotions as a sub-system could help us consider the part all-things-considered judgment overlook. [5] Furthermore, from the view of Tappolet, it has difficulties in cool akrasia lacks emotion to explain actions' rationality. For instance, if we do not take pleasure into account, it would be hard to explain smoking. She makes a distinction between emotions and beliefs and desires and insists emotion is an important factor in akratic actions. [8]

\section{OBJECTIONS FOR ARGUMENT ABOUT EMOTIONS PLAY A RATIONAL ROLE IN AKRATIC ACTIONS}

These objections are: firstly, if Davidson is right, then it is hard for better judgments as a conditional and prime facie judgments to become unconditional judgment. All-things-considered judgments may not perfect. It means apart from beliefs and desires, actions are influenced by many factors, including emotions, morality and social conventions, and so on. Therefore, the scope of reasons expands to wider, not only emotions.

Kate Nolfi (2015) agrees with this and tries to prove that the cognitive or psychological mechanisms are rationally evaluable. She distinguishes two explanations, one is the merelycausal explanation, the other is the reasons-forwhich explanation, which includes potential rational reasons, such as emotions and motivations. The psychological mechanisms admit reasons-forwhich explanation and disposition regulation account, provide rationalizing or justifying reasons for mental states. [7] It reveals that Kate has expanded the scope of being rational to include being reasonable. More arguments for this statement will be presented later.

Before making a distinction between reasonability and rationality, it is necessary to consider some problems of these arguments for the rationality of emotion in akratic actions:

The most important thing is the concept of rationality of these philosophers does not have the same meaning. Tappolet identifies intelligibility with rationality, but in her argument, she is not succeeded in proving emotion plays a rational role in akratic actions. She only proves emotion plays a reasonable role in akratic actions and she cannot explain how negative emotion plays a reasonable role in akratic actions.

Besides, that emotions' evaluative judgments conflict with better judgments, if we want to prove that even if emotions' evaluative judgments violate better judgments, emotion still is rational, then it is not clear for the arguments of these philosophers that whether better judgments do not include evaluative judgments, and how evaluative judgments take the place of better judgments. Take the case of a Ph.D. student of Arpaly, it is not convincing to prove that abandoning degree because of sadness or ill-motivation leads to better judgment.

Obviously, if emotions' evaluative judgments take the place of better judgments, then akratic action seems to disappear because akratic actions based on emotion become better judgment and do not object better judgment anymore. It is the better judgment. Therefore, that is not convincing because emotions are more complex than we thought. Some emotions have false beliefs that would lead to akratic actions as well.

It is believed that the rationality of emotion regulates people's actions through theoretical and practical reasoning in search of an optimizing strategy. Although an optimizing strategy is different or conflictive for individuals and groups and rationality is a relative concept, there still have a relatively rational judgment in some situations.

\section{ARGUMENT FOR SOME EMOTIONS PLAY A REASONABLE ROLE IN AKRATIC ACTIONS}

It would be an ideal way to divide akratic actions' causes (when talking about emotions) into five categories, the first category A, mere causes, which mean physical causes, such as muscle movement or body movement. It is rational if some emotions lead to body movement. The second category B, rational causes. Akratic actions are rational when some emotions fitting with cases or tracking something vital overlooked by better judgment. The third category $\mathrm{C}$, reasonable causes, including category A and B. The fourth category D, the reasonable causes category, the part not including category A and B. The category D is including irrational emotions but play a reasonable role in akratic actions, such as excessive negative emotions, and recalcitrant emotions, etc. Category 
$\mathrm{D}$ is the most important category, which means some akratic actions' causes are not rational but reasonable, or conflict with better judgment but reasonable. (See the "Figure 1")

C

Reasonable causes

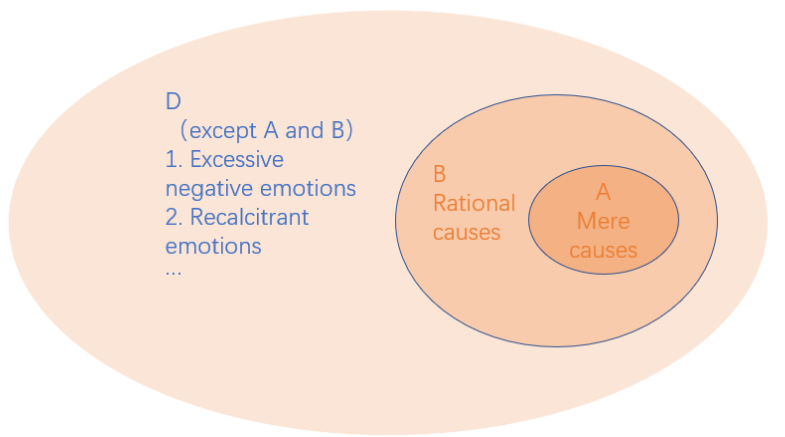

Figure 1 The categories of akratic actions' causes.

The parts of category $\mathrm{D}$ including excessive negative emotions and recalcitrant emotions, etc.:

- Excessive negative emotions, which in the irrational category of negative emotions (except the rational category of negative emotions, which should be put in the rational category). The rational category of negative emotions means fitting, for instance, when someone's friend dead, he or she will feel grief. The irrational category means mad or disruptive emotions that contribute to excessive or aggressive actions. These emotions are irrational but can be reasonable. Although this leads to the rational category narrow down, it is clearly how rational category should be.

- Recalcitrant emotions (if they cause to some actions), which conflict with evaluative judgment. For instance, someone is afraid of a bear and runs away although believing that the bear in the zoo poses no danger. Recalcitrant is irrational due to opposite with evaluative judgment. However, it is suggested that it is reasonable, the reason is when someone felt fear with bear and took some actions, even he or she just saw the sight of the ferocious bear, it is the fitting reason why he or she felt fear and took some actions. The sight evoked his or her emotions when he or she was seeing it. Therefore, although recalcitrant emotions are irrational, these emotions are reasonable to explain akratic actions.

\section{RESPONSES FOR SOME POSSIBLE OBJECTIONS FOR THE ARGUMENT}

It is believed that there may be some objections or questions to the argument that some emotions play a reasonable role in akratic actions, and I will try to reply to these objections or questions from different aspects.

- Mere causes should not put in a reasonable and rational category. One possible reply is mere causes mean body movements, such as muscle movement. These are sufficient and necessary conditions of actions. Although some emotions do not cause actions, if emotions cause body movements, body movements can be rational actions. By contrast, some philosophers assert body movements cause emotions. Nevertheless, they would not object body movements are rational to be explained by emotions. Therefore, mere causes should be maintained in the rational category.

- Why rational and reasonable causes categories not independent of each other? One possible reply is category D has revealed that some emotions are irrational but reasonable. They have false beliefs and cannot be justified by beliefs and desires. Besides, reasonable causes embody rational causes and reasons-for-which (the cognitive or psychological mechanisms). Therefore, the reasonable category larger than the rational category and embraces the rational category.

- The category of reasonable causes is too large and whether it should be embraced by 
mere causes? One possible reply is although mere causes are rational, reasonable causes category is larger than mere physical causes, the reasonable causes category involves the cognitive or psychological mechanisms or social conventions. Physicalists may deny this view, but they will not object that would be a big burden to introduce social or psychological factors when explaining the reasonableness of actions. That is enough for the explanation of the category of reasonable causes.

- Whether has a clear boundary between negative emotions in the rational category and negative emotions in the reasonable category? One possible reply is that obvious distinction is moderation of negative emotions. Unfortunately, we have to find the clear boundary in virtue of ordinary experience and that is a hard work. Nevertheless, the distinction between excessive and moderate triggers the distinction between negative emotions in the rational category and negative emotions in the reasonable category. Therefore, these distinctions are necessary.

- In the category $\mathrm{D}$, if these emotions do not cause to akratic action, then whether these divisions failed? One possible reply is although presupposing these emotions lead to akratic actions, and actions may not happen just because cognitive or evaluative judgment made by emotions, these irrational emotions may lead to akratic actions. Besides, more researches are needed to prove that whether emotions are cognitive or evaluative judgments, or something else, which could lead to akratic actions.

The method of dividing categories has some advantages. Firstly, the rational causes category and reasonable causes category reveal that actions based on emotions not rational all the time, that may be just in the reasonable category. Which object argument about 'emotions play a rational role in akratic actions.' Secondly, if akratic actions have emotions, then emotions may take the place of better judgment to be new better judgment, and actions not violate better judgment. But it is doubtful whether akratic action disappears. To preserve the possibility of akratic actions, category D must exist in akratic actions, for these emotion causes in category D have false beliefs and violate better judgment, which prove akratic actions are possible. Therefore, the method could object rational argument and maintain the possibility of akratic actions.

However, there are some premises had been presupposed in these categories, including assumed akratic actions embody emotions and not focused on cool akrasia; admitted emotions cause to akratic actions. If possible, more researches are needed about these.

\section{CONCLUSION}

According to Davidson's argument, akratic actions are possible but irrational. But although akratic actions are possible, some of them are rational. Because some emotions fitting with cases or tracking something vital overlooked by better judgment. However, there are some irrational emotions could only play a reasonable role in akratic actions. But they are mistaken for play a rational role in akratic actions from the view of Nomy Arpaly, Karen Jones and Christine Tappolet, etc. Therefore, it is better to narrow down the concept of "rational" and make room for the concept of "reasonable" to avoid the confusion that some irrational emotions play a rational role in akratic actions.

However, more researches are needed to deal with some left problems. Whether the elements of category D are right and what else could be put in this category? What has in the no-reasonable category? If emotions are not judgment and not more rational than better judgment, whether the argument fail? What are the reasons for emotions, and whether emotions just play a casual role in akratic actions?

\section{AUTHORS' CONTRIBUTIONS}

This paper is independently completed by $\mathrm{Yu}$ Zhang.

\section{REFERENCES}

[1] Arpaly, N., 2000, "On Acting Rationally Against One's Better Judgment," Ethics, 110: $504 ; 512$.

[2] Bennett, J., 1974, "The Conscience of Huckleberry Finn," Philosophy, 49: 125.

[3] Davidson, D., 1970, "How Is Weakness of the Will Possible?" in Davidson, 1980, pp. 38-42.

[4] Davidson, D., 1982, "Paradoxes of Irrationality" in Ernie Lepore and Kirk 
Ludwig (eds.), The Essential Davidson, Oxford: Clarendon Press, 2006, p. 151.

[5] Jones, K., 2003, "Emotion, Weakness of Will, and the Normative Conception of Agency" in Anthony Hatzimoysis (eds.), Philosophy and the Emotions, Cambridge: Cambridge University Press, p. 188.

[6] McIntyre, A., 1990, "Is Akratic Action Always Irrational?" in O. Flanagan and A. Rorty (eds.), Identity, Character, and Morality, Cambridge, MA: MIT Press, p. 380.

[7] Nolfi, K., 2015, "Which Mental States are Rationality Evaluable, and Why?" Philosophical Issues, 25:60.

[8] Tappolet, C., 2003, "Emotions and the Intelligibility of Akratic Action," in S. Stroud and C. Tappolet (eds.), Weakness of Will and Practical Irrationality, Oxford: Oxford University Press. p. 119. 